\title{
Saborido, Jorge. La Revolución Rusa cien años después: historia e interpretaciones del acontecimiento más importante del siglo XX.1ed.- Ciudad Autónoma de Buenos Aires: Eudeba. 2017. 408 p.
}

\author{
Javier Bonafina \\ Universidad Torcuato Di Tella, Argentina \\ javierbonafina@gmail.com
}

Jorge Saborido, arremete nuevamente contra los grandes dilemas del siglo XX. Escribir sobre la Revolución Rusa es cosa de audaces o de locos. Sabe que escribe bajo presiones indescriptibles, y que cuando se encuentra dominado por la idea de que debe narrar momentos de cambios, debe tener presente que no sólo se trata de representar tiempos de hazañas fabulosas, sino fundamentalmente de que esas hazañas no lo transformen en un vengador del futuro, un juez que se presenta ante las partes, levantando a los caídos y derribando a los soberbios.

Por eso, hace bien en centrarse en los procesos histórico-sociales de modernización y arcaísmo, industrialización y ruralización, dirigidos hacia el progreso y el atraso conservador de la clase política: Fenómenos que caracterizaron la Historia Rusa del Siglo XX y que ya estaban presentes en el siglo XIX, en forma de contraste entre la acción reformadora y la inmovilidad del poder zarista que fueron desafiados por La Revolución.

El análisis del autor pone la mirada en estas peculiaridades históricas e introduce al lector en las reformas relacionadas con la administración local, la educación, la justicia y el ejército que respondieron a la necesidad de centralizar y unificar un imperio compuesto - principalmente- de campesinos en condiciones de servidumbre.

Las modalidades específicas de la industrialización rusa, la consiguiente diferenciación del mundo rural y la formación de varias orientaciones políticas, transformó y diversificó a la sociedad por completo durante la última década del siglo XIX. La consecuencia de la nueva efervescencia política y social dentro del Estado zarista se tradujo, por lo tanto, en la combinación de dos elementos antitéticos pero inamovibles característicos del camino de la identidad rusa. Por un lado, Rusia entró en el siglo XX como un Estado en un proceso de fermentación, transformado socialmente, caracterizado por las formaciones de partidos políticos modernos y las respectivas demandas económicas y salariales. Por otro lado, la promoción y la exaltación de la concepción autocrática y personalista de la figura del zar continuaron siendo una representación del poder y la sociedad anacrónicos y obsoletos que derivó, por consiguiente, en la polarización y agudización de profundas hostilidades existentes entre diferentes y diversas clases sociales.

Por esta razón, los acontecimientos de 1905-1907, los años del comienzo de la crisis del régimen, se definieron e interpretaron como años revolucionarios. Junto con las solicitudes de una mayor protección de los derechos civiles y las libertades constitucionales, las demandas salariales y laborales vinculadas a la industrialización fueron variadas, mientras que las reclamaciones y protestas de emancipación también provinieron de la gran cantidad de nacionalidades periféricas que conforman el inmenso territorio ruso. 
Además, durante las huelgas, los campesinos se unieron por primera vez al movimiento obrero y la movilización estudiantil. El espectro de la revolución en el campo, fue un shock para los conservadores y para el propio zar. De hecho, la movilización mostró cómo los campesinos se habían convertido en una fuerza autónoma, capaz de coordinarse y autogestionarse a pesar del atraso económico y laboral del campo.

Pero los verdaderos protagonistas de la primera revolución rusa fueron, sin duda, los partidos. Cuyo accionar se visibiliza en los momentos de mayor tensión. La revolución de 1905 coincidió parcialmente con la guerra ruso-japonesa; ya había comenzado cuando se produjo la debacle rusa en extremo oriente; aunque las noticias de la derrota contribuyeron a exaltar más los ánimos. Los principales representantes de la oposición gubernamental, una oposición eslavófila y populista, exigieron el establecimiento de un cuerpo representativo con poderes legislativos, junto con una expansión de la Ley electoral y la concesión de una Constitución.

$\mathrm{Al}$ mismo tiempo que las demandas de los "constitucionalistas", estallaron las huelgas en las principales ciudades del imperio que involucraban a trabajadores y movimientos sindicales nacientes. Además, en las regiones periféricas del Imperio, las reclamaciones se mezclaron con los movimientos nacionales no rusos que requerían concesiones lingüísticas y autónomas.

Eventos diferentes indicaban, por lo tanto, cómo la sociedad y el gobierno zarista habían alcanzado un momento nodal de su modernización. El régimen zarista mostró todas sus debilidades estructurales y su incapacidad para proporcionar respuestas a los proyectos nacientes de la reforma constitucional.

Saborido muestra como las fuerzas en pugna le arrancan al zar, en agosto de 1905, la fundación del primer cuerpo representativo, la Duma, con poderes legislativos. Sin dudas, representaba una primera concesión significativa a las fuerzas políticas de la oposición. Tras la intensificación de las huelgas y protestas de octubre de 1905, también se estableció en San Petersburgo el primer sóviet de diputados obreros. La primera experiencia de los soviéticos, el cuerpo de un consejo obrero, estuvo marcada por el deseo de unificar el amplio movimiento de protesta, gracias al aporte de los socialistas mencheviques y bolcheviques, partidarios de la agitación en curso.

El poder autocrático, permaneció demasiado distante de las demandas de los diputados y del pueblo. Como resultado, las dos primeras Dumas fueron mayoritariamente opositoras y forzaron a buscar una solución, lo que derivó en la ley electoral de 1907. Estas tensiones quedaron simbolizadas por la figura del Ministro del Interior y luego Primer Ministro Pëtr Stolypin. El constitucionalismo Stolipiniano, se inspiró en el modelo bismarckiano de centralización y estabilización y tuvo como primer objetivo la construcción de un bloque partidario oficial para la competencia electoral. El propósito de esta coalición era, de hecho, la consolidación de una nueva estabilidad social dirigida a reprimir los impulsos revolucionarios que ocurrieron.

La nueva ley electoral, en consecuencia, redujo los espacios de disidencia, pero abrió el camino a la cohesión del ejecutivo y al cambio, a la metamorfosis industrial y empresarial del país. La "modernización", resultó ser una síntesis de autocracia restringida y parlamentarismo. Su intención era erradicar el atraso económico y social en el campo para formar una clase media de campesinos, burgueses, fieles al régimen zarista.

La formación de un Estado compacto, capaz de proteger los intereses de las clases más ricas y capaz de canalizar el consenso campesino hacia el régimen, tenía el objetivo de disipar el espectro de nuevos momentos de agitación. Esto se anudaba con la exaltación de una nueva cohesión nacional rusa, una nueva "idea rusa" robusta y compacta, diferente de la variedad étnica que componía, y aún compone, el territorio ruso.

El Profesor Saborido reconstruye, hábilmente, el complejo proceso de nacionalización de las masas, la ruptura entre la sociedad y el Estado, entre la Duma y el zar. El cuerpo legislativo seguía siendo un componente frágil y débil, aunque parecía encarnar el símbolo del progreso legal y el desmantelamiento de los privilegios de los tribunales, incapaz de ejercer una actividad legislativa autónoma. La figura de Stolypin hizo que el zar se escudara aún más en la defensa de su figura absolutista, erosionando la imagen de la dinastía Romanov y la escalada de hostilidades dentro de la sociedad. En este clima de inquietud, en 1911, se produjo el asesinato de Stolypin y la reapertura de una fase constitucional incierta y agitada, que habría catalizado el camino hacia la desintegración. 
El autor retorna a mostrarnos la fuerza del impacto de la Primera Guerra Mundial, en el destino del Imperio zarista, en virtud de las contradicciones presentes en su desarrollo y de los conflictos que desgarraron el tejido social. Los años de la guerra no son sólo el momento catalítico de la caída del régimen zarista, sino también el período de gestación de prácticas administrativas, gubernamentales y métodos de intervención estatal, caracterizados por un liderazgo marcado, una propensión a la ingeniería social y la "militarización" de todos los aspectos de la vida colectiva. Haciendo evidentes las ineficiencias, fragilidad y rigidez en sectores cruciales como el aparato de producción industrial, las comunicaciones y el transporte.

El Historiador encuentra en 1917 un año crucial y esto lo lleva a hablar de un conjunto de revoluciones larvadas. Petrogrado, con su peculiar geografía urbana y social, es la protagonista indiscutible de la revolución. En los meses posteriores a la Revolución de febrero, la politización de la sociedad creció considerablemente. La politización radicalizó a los trabajadores, haciéndolos permeables a la propaganda bolchevique.

En una escalada que concentró riesgo y oportunidad, Lenin radicalizó el conflicto. La radicalización social, exacerbada por el creciente flujo de desertores, alimentada por las decepcionadas expectativas de pan, paz y tierra y favorecida por la crisis del poder central, dio lugar a la demanda de autodeterminación popular en todos los niveles.

Vistos desde la óptica Braudeliana, cien años no parece demasiado tiempo, aunque es más que suficiente para evaluar la efectividad de una estrategia a largo plazo. Lenin tenía una estrategia que apuntaba a la revolución mundial y, aunque creía en una rápida expansión en los países avanzados de Europa continental, descartaba la idea de que esto ocurriría en todo el mundo (o casi) y que requeriría un período mucho más largo.

Saborido, a lo largo del texto, nos interpela desde sus propias dudas y certezas: La convicción sobre la inevitabilidad histórica de la revolución fue, en parte, producto del Historicismo Marxista, para el cual la Historia es una sucesión inevitable de diferentes sistemas de producción, determinada por la evolución de las capacidades de producción: cuando un sistema ya no es compatible con la evolución de los medios de producción, se hace necesario reemplazarlo por otro más adecuado y, dado que esto implica una sucesión de clases dominantes, y los que están en el poder no están dispuestos a hacerse a un lado, por lo que el cambio debe realizarse de manera violenta.

La historia de los últimos dos siglos, sin embargo, no ha confirmado muchos de los supuestos básicos de esta teoría del cambio social. En primer lugar, el capitalismo, en lo más alto de su fase de desarrollo no llega nunca al momento que no es capaz de gobernar el desarrollo de las fuerzas productivas, demostrando ser mucho más vital de lo que pensábamos. La idea de un capitalismo agonizante ha sido negada rotundamente por la capacidad del capitalismo para adaptarse a las diversas revoluciones tecnológicas que se produjeron en los últimos 150 años. Parece que lo único que el Capitalismo sabe hacer es gozar de buena salud.

En el fenómeno descrito por Freud en "Los que fracasan cuando triunfan" (1916), no hay duda acerca del vínculo entre la enfermedad y el éxito. Justo cuando está a punto de realizar su deseo, el sujeto enferma y surge el fracaso, como si la dicha no pudiera ser soportada. El destino ataca la posibilidad quien desea ahí donde el éxito estaba al alcance de la mano. No se trata del deseo que circula en la fantasía, sino de la realización del deseo por el acto mismo. Esta parece ser la resonancia de la Revolución Rusa. En última instancia, ninguna revolución o proceso revolucionario alcanza los ideales y la visión defendidos por sus seguidores iniciales. Las revoluciones avanzan y se retiran bajo el peso de realidades y contradicciones internas y externas, hasta la llegada a un estado de equilibrio en conformidad con las limitaciones impuestas por las restricciones culturales y económicas particulares del espacio y el tiempo en que ocurren.

Finalmente, ¿Por qué hay que leer este libro, un libro más, sobre la Revolución Rusa? Quizás, porque establece los fundamentos de las relaciones entre las conexiones. Porque mientras se avanza en su lectura se descubren influencias de otros escritores y otras grandes obras. Por supuesto, esto está relacionado en parte con el atractivo universal de leer un buen libro. Pero, además se nutre de todos los debates sobre la Revolución, ya sea de manera inconsciente o específicamente trabajada en la trama del texto. Del mismo modo, es una obra 
Trabajos y Comunicaciones, 2da. Época, No 50, e100, julio-diciembre 2019. ISSN 2346-8971

que inspirará a otros historiadores e incluso a escritores que vendrán luego, y podremos rastrear así, cómo influyó en las obras de su propio tiempo y en la de los tiempos posteriores. 